\title{
Metalingvistiline teadlikkus võõrkeeleõppes: oma keel võõras peeglis
}

\author{
ANNEKATRIN KAIVAPALU \\ Tallinna Ülikool
}

Ülevaade. Käesoleva artikli eesmärgiks on uurida, milliseid tähelepanekuid teeb õppija võõrkeeli õppides oma emakeele, antud juhul eesti ja soome keele kohta ning kas ja millises osas ühtivad õppijate arusaamad keelte lingvistiliste kirjeldustega. Oma seisukohti väljendasid esseedes teemal "Äidinkieli vieraiden kielten opiskelussa - etu vai haitta?/Emakeel võõrkeeleõppes - eelis või takistus?” Tallinna ülikooli soome keele eriala ja Jyväskylä ülikooli keelte õppetooli üliõpilased. Neist kümne emakeel oli eesti keel ja seitsme emakeel soome keel; sihtkeeltena olid uurimuses osalejad õppinud erinevas mahus eesti, soome, soome viipekeelt; germaani keeltest inglise, saksa, rootsi, norra keelt; romaani keeltest prantsuse, hispaania, portugali, itaalia keelt; slaavi keeltest vene, poola, bulgaaria keelt.

Õppijate tähelepanekud oma emakeele ja sihtkeelte erinevuste ning sarnasuste kohta langesid paljuski kokku keelte tüpoloogiliste struktuurierinevustega. Õppijate jaoks aktiveerusid indoeuroopa keelte õppimise käigus eelkõige teadmised soomeugri keelte sarnaste ning indoeuroopa keeltest puuduvate või erinevate keelenähtuste kohta, aga ka eesti ja soome keele toimimispõhimõtete omavaheline sarnasus ning erinevus indoeuroopa keeltest. Tähelepanekud hõlmasid kõiki keeletasandeid, kuid eriti rõhutatult toodi esile soomeugri keelte morfoloogiakesksus. Lähedaste sugulaskeelte võrdluses tulid esile vähesed struktuurierinevused, 
kuid peamiselt puudutasid õppijate tähelepanekud pragmaatilisi ja sotsiolingvistilisi erinevusi.

Võtmesõnad: metalingvistiline teadlikkus; õppija arusaamad; võõrkeeleõpe; keeltevaheline tegelik ja tunnetatud sarnasus; eesti keel; soome keel

\section{Metalingvistiline teadlikkus ja õppija arusaamad}

Viimastel aastakümnetel sihtkeele omandamise uurimises toimunud tähtsaim muutus seisneb tõdemuses, et keeleõppijat ei käsitata enam mehhanismina, mida läbivad sisendi ja väljundina teatud struktuurid (Pavlenko, Lantolf 2002: 155). Õppija on eesmärgikindel, toimiv ja inimlik olend, õppimise subjekt, kes võtab endale vastutuse oma õppimise tulemuslikkuse eest: ta on võimeline eesmärgistama õppeprotsessi, seatud eesmärke järgima ja vajadusel korrigeerima, hindama oma keeleoskuse arengut ning analüüsima iseennast keelõppija ja -kasutajana (Kalaja, Dufva, Alanen 2005: 295).

Teise keele omandajad ja võorkeele õppijad on reeglina oma emakeele oskuslikud valdajad. Neist igaühel on keeleoskus, millest piisab toimetulekuks tuttavates olukordades, ning vähemalt intuitsioon sellest, milleks ja kuidas inimesed keelt kasutavad, millist keelt nad kasutavad ja millist keelt õppija ise oskab või ei oska või võiks osata. Lisaks on igaühel oma arusaam keelest ja keelekasutusest.

Emakeele omandab inimene tavaliselt varases lapseeas ilma teadliku õpetuseta. Emakeele süsteemi kujundab laps ise ümbritseva keelekasutuse põhjal ning võimalused seda väljastpoolt mõjutada on üsnagi piiratud. Nii omandatakse keele struktuur (grammatika) ja põhiosa sõnavarast. Hiljem areneb selle juba kujunenud süsteemi kõrvale kooli emakeeleõpetuse abil teinegi süsteem, mis erinevalt eelnevast põhineb analüütilisel tegevusel. Selle süsteemi kujunemist on võimalik teadlikult suunata, juhtides õppija tähelepanu vajalikele üksikasjadele. Emakeele süsteem ei ole niisiis sugugi püsiv ega muutumatu, vaid võib areneda esialgsest vägagi erinevaks. Emakeeleõpetus muudab ja mitmekesistab 
õppija seniseid oletusi ja arvamusi emakeele kohta ning seejuures kujundab ka arusaama, kuidas inimkeel kui selline üldse toimib. (Sajavaara 2006: 20-21) Esmajoones emakeele põhjal kujuneb õppija metalingvistiline teadlikkus ${ }^{1}$ : teadmised emakeele ja teiste keelte, keelte sarnasuse ja erinevuse ning keele toimimismehhanismide kohta.

Sihtkeelt õppides avardub õppija metalingvistiline teadlikkus kahes suunas: samal ajal, kui omandatakse teadmisi ja oskusi õpitava keele kohta, suureneb ka teadlikkus oma emakeele osas: õppija hakkab märkama emakeele erijooni, mis on varases eas omandatud ja seetõttu automatiseerunud ning millele tavaliselt tähelepanu ei pöörata (Kaikkonen 2004). Käesolevas artiklis keskendutakse viimasele metalingvistilise teadlikkuse komponendile: artikli eesmärgiks on uurida, milliseid tähelepanekuid teeb õppija võõrkeeli õppides oma emakeele, antud juhul eesti ja soome keele kohta.

Metalingvistilise teadlikkuse, õppija (argi)teadmise, arusaamade ning kogemuse olulisust ja kasutatavust sihtkeele õppes on rõhutatud erinevates seostes (nt Sajavaara 1994: 22; Kalaja 1995: 68, Dufva, Lähteenmäki, Isoherranen 1996: 82). Arvatakse, et õppija toetumine oma kogemustele ja teadlikkuse kasv aitavad kaasa motiveeritud ja efektiivsele õppimisele (nt James, Garret 1991). Sihtkeele õppimise uurijate huvi õppijate arusaamade (ingl beliefs, sm käsitykset) vastu keele õppimist mõjutava tegurina sai alguse 1980. aastatel (uurimissuundadest täpsemalt vt Kalaja, Barcelos 2003). Peamiselt on diskuteeritud arusaamade olemuse üle: kas õppija arusaam on kognitiivne või pigem sotsiaalne; kas see on õppija omadus nagu suhtumine ja motivatsioon, või hoopis keeleline toiming, käsitus, mida õppija võib kasutada erinevatel eesmärkidel ja olukordades (Kalaja, Dufva, Alanen 2005: 295). Käesolevas artiklis on õppijate arusaamu käsitatud diskursiivsetena: õppijate keeleõppimise kogemuste põhjal konstrueerituna ja kirjeldatuna, kuid samas paljuski sotsiaalsetena ja kultuurikesksetena. (Kalaja, Dufva, Alanen 2005: 295)

Erinevates allikates on samas tähenduses kasutatud ka terminit metakognitiivne teadlikkus (vt nt Wenden 1987) 
Varasemates uurimustes on tõdetud, et õppijad suudavad kirjeldada oma arusaamu nii emakeelest (Kaivapalu, Muikku-Werner 2000) kui ka sihtkeele õppimisest ( Dufva, Lähteenmäki, Isoherranen 1996; Kaivapalu 2006; 2007) eeldatust tunduvalt paremini, ka siis, kui nad ei valda lingvistilist terminoloogiat. Kui erinevate inimeste arusaamu võõrkeeltest ja nende õppimisest on uuritud üsna palju, siis keelekasutajate arvamusi emakeele ja selle tähenduse kohta on käsitletud hoopis vähem. Eesti ja soome üliõpilaste arusaamade võrdlev uurimine (Kaivapalu, MuikkuWerner 2000: 102-103) osutas, et õppijate arusaamad olid omavahel üsna sarnased: mõlema keele kõnelejatel oli väga üksikasjaline käsitus emakeelest ja sihttkeeltest, nendes keeltes suhtlemisest ja vastastikusest mõjust. Erinevusi ilmnes eestlaste emotsionaalsemas suhtumises oma emakeelde, emakeele väärtustamises eelkõige rahvusliku identiteedi kandja ja suhtlemis- ning mõtlemisvahendina, samuti pidasid eestlased ennast teadlikumateks keelekasutajateks kui soomlased.

Käesolevas artiklis käsitletakse õppijate arusaamu oma emakeele kohta veidi erinevast vaatenurgast, otsides vastuseid järgmistele küsimustele:

1) milliseid emakeele erijooni eestlased ja soomlased võõrkeeli õppides teadvustavad;

2) kas ja millises osas õppijate arusaamad ühtivad keelte lingvistiliste kirjeldustega, ehk teisisõnu, milline on omavaheline suhe tegeliku ja tunnetatud sarnasuse ning erinevuse vahel.

Küsimus on muu hulgas siis selles, milline on teadusliku teadmise ja argiteadmise omavaheline suhe.

\section{Tegelik, tunnetatud ja oletatav sarnasus}

Kuigi lingvistid ja keeleõpetajad on aastasadu koostanud keelte võrdlevaid kirjeldusi, on kontrastiivses analüüsis vaatlemist ja teadvustamist peetud relevantseks alles viimastel kümnenditel (Odlin 1996: 176). Ka eesti ja soome keele süsteemide võrdlevaid uurimusi on üsna katvalt 
nii Lähivertailuja-sarjas kui ulatuslikemates üksikuurimustes (Remes 2009), kuid lähedase sugulaskeele omandamise uurimisele on need aluseks olnud vaid üksikjuhtudel (Kaivapalu 2005). Uut keelt õppima asudes tugineb keeleõppija intuitiivselt nendele teadmistele ja oskustele, mis tal emakeelest ja teistest varem omandatud keeltest juba olemas on, ning püüab leida keeltevahelisi sarnasusi. Õpetamisel seevastu keskendutakse eelkõige keeltevahelistele erinevustele. Seetõttu on keeltevahelise mõju uurimises viimasel ajal tähelepanu keskmesse tõusnud keeltevahelise tegeliku (objektiivse) ja tunnetatud sarnasuse ning erinevuse eristamise vajadus (Ringbom 2007: 7-9, 24-26).

Tegelik ehk objektiivne sarnasus (ingl actual/objective similarity) kuulub lingvistika valdkonda ning seda on võimalik vähemalt teoreetiliselt keelesüsteemide võrdluse põhjal täpselt määratleda (nt eesti ja soome morfoloogiasüsteemide võrdlus Remes 2009). Kui tegelik keeltevaheline sarnasus eksisteerib, siis on see sümmeetriline.

Tunnetatud sarnasus (ingl perceived similarity) seevastu ei pruugi olla tingimata sümmeetriline: keele $\mathrm{X}$ kõnelejate jaoks võib arusaamine keelest Y olla mingil põhjusel lihtsam kui keele Y kõnelejatele arusaamine keelest X. Viis, kuidas keeleõppija keelesüsteemide tegelikku sarnasust tajub, on tegelikust sarnasusest tunduvalt laiem ning suuremat variatsiooni sisaldav psühholingvistiline mõiste. Seetõttu on tunnetatud sarnasusest rääkides sageli kasutatud termineid psühhotüpoloogia ( $p s y$ chotypology) (Eckman 2004: 517) ja sarnasuse psühholingvistiline reaalsus (Kaivapalu 2004: 65-70; Sajavaara 2006: 14). Tunnetatud sarnasust on raskem määratleda, kuna see sõltub paljuski õppijate individuaalsetest iseärasustest.

Keeleloomes, eriti lähtekeelest oluliselt erineva sihtkeele puhul, on olulisem oletatav sarnasus (ingl assumed similarity), mis nagu tunnetatud sarnasuski kuulub psühholingvistika valdkonda. Oletatav sarnasus võib põhineda ja sageli põhinebki tunnetatud sarnasusel, kuigi see ei pruugi alati nii olla. Kui õppija ei tunneta sarnasusi lähte- ja sihtkeele vahel, oletab ta, et sihtkeel toimib ligikaudu samamoodi kui lähtekeel(ed). Kui oletus ei pea paika, põhjustab see vigu õppija keeleloomes. 
Kui tegelik sarnasus ja erinevus on keelestruktuuride objektiivne omadus, siis tunnetatud sarnasus ja erinevus põhinevad õppija arusaamadel. Tegelik ja tunnetatud sarnasus ja erinevus võivad, kuid ei tarvitse kokku langeda. Nii tunnetasid enam kui pooled eestikeelsetest soome keele õppijatest ja soomekeelsetest eesti keele õppijatest sarnastena aglutineerimisprotsessi eesti ja soome mitmuse vorme koolides - kouluissa, laevadel - laivoilla, peresid - perheitä, paikadest - paikoista, teistel - toisilla, sõltumata sellest, millise konkreetse mitmuse tunnusega tegemist on (Kaivapalu 2004: 67-68). Samuti võib eestikeelne soome keele õppija produtseerida soome keele vokaaltüvelise $i$-mitmuse vormi laine/i/sta eesti keele konsonanttüvelise de-mitmuse vormi lain/te/st analoogia põhjal (Kaivapalu 2005: 270 ):

(1) laine laineja laineista ei laineista laineista. laineista, selle sõna puhul ma oletan, et see tähendab lainet ja siis ja siis laintest oleks eesti keele seestütlev. Ma teen siis seestütleva eesti keele järgi: laineista.

Keeleõppe ja keeleõppija seisukohalt on tunnetatud ja oletataval sarnasusel tunduvalt ulatuslikum ning otsesem roll kui keelesüsteemide tegelikul sarnasusel (Sajavaara 1994: 22; 2006: 16). Keele õppimine ei ole kunagi pelgalt lingvistiline nähtus. Lähte- ja sihtkeele kontrastiivsus realiseerub õppija kognitiivses süsteemis tema teadmisena, kogemusena, tõlgendusena, oletusena. Õppija arusaamad ja kogemused aga on tihedalt seotud tema metalingvistilise teadlikkusega, käsitusega keelest kui nähtusest ja selle toimimisest. Õppekeskkonnas on täheldatud, et kontrastiivne metalingvistiline teadlikkus aitab õppijal tulla toime raskusi valmistavate probleemidega, kui rõhutatakse emakeelest erinevaid sihtkeele ilminguid ja pööratakse neile tähelepanu (Kupferberg 1999; Spada, Lightbown 1999). Ka varem omandatud võõrkeelte teadmiste aktiveerimisest on õppijale abi (Jessner 1999). Sellepärast on oluline selgitada, mida õppijad teadvustavad oma emakeelest seda teiste keeltega võrreldes. 


\section{Uurimuse metodoloogia}

Õppijate arusaamade uurimine ankeetküsitluste abil on varasemates uurimustes (Muikku-Werner 1995; Kaivapalu, Muikku-Werner 2000) osutunud mõneski mõttes puudulikuks lahenduseks: vastused on sageli väga lühikesed ja konstanteerivad ning jäävad põhjendamata. Seetôttu valiti käesolevas uurimuses õppija arusaamade selgitamise ainestikuks esseed teemal "Äidinkieli vieraiden kielten opiskelussa - etu vai haitta? Emakeel võõrkeeleõppes - eelis või takistus?”. Essee vorm võimaldas piiramatult avaldada oma arvamust emakeele rolli kohta võõrkeeleõppes ja seda ka põhjendada. Piisavalt üldisena formuleeritud pealkiri lubas käsitleda probleemi erinevaid aspekte ilma, et oleks juhtinud kirjutajate tähelepanu käesoleva artikli uurimisküsimustele. Tegemist on siis õppijate spontaansete mõtetega, mis kaasnesid emakeele rolli analüüsimisega.

Oma seisukohti väljendasid esseedes Tallinna ülikooli soome keele eriala ja Jyväskylä ülikooli keelte õppetooli üliõpilased. Neist kümne emakeel oli eesti keel ja seitsme emakeel soome keel; sihtkeeltena olid uurimuses osalejad õppinud erinevas mahus eesti, soome, soome viipekeelt; germaani keeltest inglise, saksa, rootsi, norra keelt; romaani keeltest prantsuse, hispaania, portugali, itaalia keelt; slaavi keeltest vene, poola, bulgaaria keelt. Tegemist oli siis mitmeid tüpoloogiliselt erinevaid keeli õppinud ja erinevalt tasemel oskavate lingvistidega, kelle metalingvistiline teadlikkus oli tavapärasest kõrgem.

Soomekeelsed üliõpilased kirjutasid oma esseed soome keeles, eestikeelsed üliõpilased kas eesti või soome keeles. Alljärgnevad tsitaadid esseedest on esitatud mõlemas keeles muutmata kujul. Lisaks tsitaatidele väljendavad ka kursiivis olevad tekstikatked óppijate seisukohti nende oma sõnastuses. Näidete järel sulgudes olev lühend tähistab kirjutaja koduülikooli (J - Jyväskylän yliopisto; T - Tallinnan yliopisto) ning viitab samas üheselt õppija emakeelele, vastavalt soome või eesti keelele. Analüüs on ainestikust tulenevalt esmajoones tõlgendav. 


\section{Oma keel võõras peeglis}

\subsection{Soomeugri keeled indoeuroopa peeglis}

Nii eesti- kui soomekeelsed õppijad olid õppinud mitmeid indoeuroopa keeli, puutunud kokku soomeugri ja indoeuroopa keelte struktuurierinevustega ning lingvistikaüliõpilastena vägagi teadlikud sellest, millised indoeuroopa keeltes esinevad grammatilised kategooriad ja kategoriaalsed vormid nende emakeelest puuduvad. Eraldi toodi välja sookategooria, artiklid ja prepositsioonid:

(2) Kuna eesti keeles puudub sookategooria, tuleb näiteks saksa keele õppimisel sõna sugu pähe õppida. (T)

(3) Kaiken kaikkiaan ongelma kuitenkin johtui siitä, että suomen kielessä yksikön kolmannen persoonan pronomini ei ilmaise sukupuolta. (J)

(4) Muistan alkuaikoina jättäneeni artikkelit kokonaan kirjoittamatta, koska en katsonut niillä olevan minkäänlaista merkitystä. (J)

(5) Englannin kielessä olen aina mieltänyt vaikeiksi prepositiot [...], joita suomen kielessä ei ole. (J)

Õppijate arvates olid oma emakeelest puuduvad kategooriad ja kategoriaalsed vormid keeleõppe seisukohalt vähemalt esialgu harjumatud ja seetõttu ka raskemini omandatavad. Seega kinnitavad õppijate kogemused ja arusaamad ühelt poolt strukturalistlik-kontrastiivse teooria seisukohta emakeelest puuduvate keelendite keerulisusest õppija jaoks (Martin 1996a: 115), teisalt aga Competition Modeli arusaama sihtkeele omandamisest kui õppija emakeele süsteemi ümberstruktureerimisest (MacWhinney 1990).

Õppijate tähelepanekud oma emakeele struktuurierinevustest võrreldes indoeuroopa keeltega hõlmasid kõiki keeletasandeid alates häälikusüsteemist ja lõpetades lausetasandiga. Eraldi rõhutati eesti ja soome keele häälikusüsteemi ja ortograafia vastavust: põhimõte on see, et loetakse nagu kirjutatakse ja vastupidi: 
(6) Suomalaisethan lausuvat sanat siten kuin ne kirjoitetaan. (J)

(7) Eestlastel on häälikkiri, s.o kirjasüsteem, milles iga märk (täht) vastab ligikaudu ühele või paarile lähedasele häälikule. (T)

Huvitaval kombel on emakeele häälikusüsteemi ja ortograafia vastavusest olnud abi isegi inglise keele ortograafia omandamisel:

(8) Ollessani vaihto-oppilaana Yhdysvalloissa englanninopettajani ihmettelikin, miten oikeinkirjoitus näytti olevan minulle niin vaivatonta, kun se tuottaa niin paljon ongelmia englantia äidinkelenään puhuville. Selitin hänelle suomen äännevastavuutta ja kerroin opetelleeni lausumaan sanat mielessäni suomeksi. Koska suomessa kirjoitetun voi lausua vain yhdellä tavalla, ei monitulkintasuutta synny. Toisin kuin amerikkalaisen, minun ei tarvinnut miettiä, kuinka monin eri tavoin kirjoitettuna sana yhä kuulostaa ääneen lausuttuna samalta ja mikä kenties olisi se oikea vaihtoehto, vaan pystyin lausumaan sanan mielessäni suomeksi ja kirjoittamaan sen mukaan. (J)

Viimase aja uurimistulemuste põhjal (nt Jong, Steinel, Florijn, Hulstijn, Schoonen 2009) on selgunud, et keeleõppija hääldus otsustab suures osas emakeelse keelekasutaja hinnangu õppija sihtkeeleoskusele tervikuna. Õppijate kogemused näitavad lisaks, et prosoodial on oluline roll keeltevahelise sarnasuse ja erinevuse tajumisel:

(9) Soome ja eesti keeles on rõhk sõnadel alati esimesel silbil, sama on ka näiteks ungari keeles, seetõttu võivad kõrvalisele isikule need keeled ühtmoodi tunduda. (T)

Muutemorfoloogia osas mainiti sõna morfoloogilist struktuuri, mis koondab keelekasutajale ja -õppijale vajaliku morfoloogilise informatsiooni sõnavormi lõppu, ning konkreetsemalt käänamissüsteemi eripära:

(10)Sanathan muodostetaan [virossa ja suomessa] melko pitkälti samalla tavalla... Suomalaisen on helppo etsiä informaatiota oikeasta paikasta, siis sanan lopusta. (J) 
(11) [---] olin aluksi hyvin hämmentynyt huomatessani, ettei englannin kielessä sanoja taivuteta.

(12)Muissa kielissähän "sijapäätteet” tai omistusmuodot ovat erillisiä sanoja lauseissa eivätkä kuten suomessa, kytkettynä itse sanaan kuten esimerkiksi sanoissa karannee/na tai epäilemättä/än. (J)

Eesti ja soome keele järjekindel ja läbipaistev tuletussüsteem lihtsustab õppijate arvates keele õppimist, sest võimaldab juba omandatut loovalt ja produktiivselt kasutada nii arusaamisel kui ka produtseerimisel (Martin 1996b). Samasuguse süsteemi puudumine sihtkeeles, antud juhul inglise keeles, seevastu põhjustab raskusi:

(13)Suurin ero tässä [englannin opiskelussa] viron kieleen ja suomen kieleen on se, että sanoja voi harvoin johtaa aiemmin opituista. (J)

(14)Viron yhdyssanat hahmottuvat suomen kielen avulla, ja siksi pitkän- ja hankalannäköisistä sanoistakin saa yleensä selvää. (J)

Eesti ja soome keele suhteliselt vaba sõnajärg oli õppijate arvates keele omandamist hõlbustav tegur, kuigi teatavasti põhjustab see isegi edasijõudnud õppijatele suuri probleeme (Sulkala 1996):

(15)Suomessa on verrattain vapaa sanajärjestys, joten on vaikeaa välillä hahmottaa muista kielistä, minne mikäkin määrite tai kieltosana olisi laitettava. (J)

(16)Syntaksin puolelta on eduksi varmaan se, että sananjärjestys on molemmissa kielissä [suomessa ja virossa] melko vapaa. $(\mathrm{T})$

Teadmine, et eesti keele süntaksis on olema-verbil oluline roll, muutub keeleõppija jaoks aktiivseks võrdluses vene keelega:

(17)Eesti keeles on aktiivselt käibel tegusõna on, vene keeles öeldakse "minu nimi Martin". (T)

Seega aktiveerusid õppijate jaoks indoeuroopa keelte õppimise käigus eelkõige teadmised soomeugri keelte sarnaste tüpoloogiliste erijoonte ja indoeuroopa keeltest puuduvate või erinevate keelenähtuste kohta, aga 
ka eesti ja soome keele toimimispõhimõtete omavaheline sarnasus ning erinevus indoeuroopa keeltest.

Tähelepanekud hõlmasid kõiki keeletasandeid, kuid eriti rõhutatult toodi esile soomeugri keelte morfoloogiakesksus: õppijate jaoks olid olulised mitte ainult teadmised struktuurierinevuste kohta, vaid ka arusaam sellest, kuidas morfoloogiasüsteem toimib ja kuhu paigutub oluline morfoloogiline informatsioon. Kui tüpoloogiliselt erinev sihtkeel järgib mingis osas emakeelest erinevat toimimismehhanismi, ei saa óppija tugineda juba olemasolevatele teadmistele, vaid tal tuleb sihtkeele toimimismehhanism alles omandada.

\subsection{Eesti keel soome keele peeglis, soome keel eesti keele peeglis}

Kuigi eesti ja soome keel lähedaste sugulaskeeltena on indoeuroopa keeltega võrreldes vägagi sarnased, erinevad need keeled õppijate arvates omavahel mitmeski mõttes. Võrdluses soome keelega märkasid eestikeelsed õppijad oma emakeele eripära nii struktuuri kui keelekasutuse tasandil. Eesti ja soome keele struktuurierinevustest mainiti eelkõige häälikusüsteemiga seonduvat:

(18)Näiteks on eesti keeles täishäälik õ, mida soome keeles pole. (T)

(19) Eesti keelt eristab teistest keeltest, ka soome keelest, kolm erinevat hääliku pikkusastet. (T)

Õppijad olid oma kogemuste põhjal teadlikud ka eesti ja soome sõnajärje olulisest erinevusest:

(20) [Virossa] voimassa on V2 -sääntö, eli verbi on toisella sijalla. (T)

Keelekasutuses oli enim probleeme tekitanud sinatamise ja teietamise erinev suhe eesti ja soome keeles, mida mainisid paljud kirjutajad:

(21)Olisi opittava myös käyttämään kielen keinoja kunkin kulttuurin odotusten mukaisesti, esim. sinuttelu ja teitittely jne. (T) 
Sugulaskeelte erinev tavapärane kõnetempo võib põhjustada raskusi arusaamisel:

(22)Eestlased räägivad kiiremini ja soomlased ei jõua sõnavahesid eraldada. (T)

Soomekeelsetele eesti keele õppijatele oli omakorda probleemiks mitme soome keele keskse nähtuse puudumine eesti keeles: vokaalharmoonia, lõpukadu ja küsipartiklid kippusid üle kanduma ka õpitavasse sugulaskeelde:

(23) Vaikeinta oli ääntäminen: vokaalisoinnun unohtaminen, sanojen loppujen poispudottaminen. $(\mathrm{J})$

(24)Jollain tasolla minulla suomalaisena oli vaikeaa sisäistää, että niin läheisessä sukukielessä ei tarvita kysymysliitteitä. kas-kysymyssanan asemesta tai jopa sen rinnalle saattoi lauseeseen yllättäen putkahtaa myös suomalainen kysymysliite. (J)

Soome keele suhteline reeglipärasus ilmnes mitte ainult võrdluses eesti keele, vaid teistegi õpitavate keeltega:

(25)Muissa kielissä on huomattavasti enemmän poikkeuksia ja "poikkeusten poikkeuksia" kuin äidinkielessämme. (J)

Samuti on sihtkeelte kontekstis õppijate meelest täiesti erandlik viisakusväljendi palun puudumine soome keeles:

(26)Esimerkiksi huomaan sen, miten suomen kielestä puuttuvat kohteliaisuussanat, erityisesti 'please' sanan vastineen puuttuminen vaikuttaa vieraiden kielten puhumiseen. (J)

Soomekeelsed õppijad on teadlikud ka sellest, et paljudes teistes keeltes ei ole sinatamine nii üldine kui nende emakeeles:

(27)Täällä ei esimerkiksi teititellä kuin erittäin harvoin, kun taas useissa muissa kielissä teitittely kuuluu asiaan lähes kaikissa tilanteissa. (J)

Lähedaste sugulaskeelte võrdluses tulid õppijate kogemuste põhjal küll esile ka (indoeuroopa keeltega võrreldes suhteliselt vähesed) struk- 
tuurierinevused, kuid peamiselt puudutasid õppijate tähelepanekud keelekasutust, pragmaatilisi ja sotsiolingvistilisi erinevusi. Erinevalt eelnevast võrdlusest indoeuroopa keeltega ei pööratud keelte struktuurielementide ja toimimismehhanismide sarnasusele eesti ja soome keele omavahelises võrdluses kuigivõrd tähelepanu. Kui tavaliselt eelneb sihtkeele omandamisel keelendi õppimine (ingl item learning) süsteemi õppimisele (system learning) (Ringbom 2007: 54-58), on lähedaste sugulaskeelte puhul põhjust oletada, et mõlemad protsessid käivituvad samaaegselt, niipea kui õppija tunnetab ja teadvustab keeltevahelist tegelikku sarnasust.

\section{Kokkuvõtteks}

Eesti- ja soomekeelsete õppijate esseedes leidis seega kinnitust seisukoht, mille põhjal sihtkeeli õppides ei omandata üksnes teadmisi õpitava keele kohta, vaid samal ajal suureneb ka teadlikkus oma emakeele erijoontest võrreldes teiste keeltega. Seejuures ei ole tegemist niivõrd uute teadmiste omandamisega oma emakeele kohta kuivõrd olemasolevate teadmiste aktiveerumisega keeltevahelise võrdluse tulemusena. Tervikuna kasvab nii õppija metalingvistiline teadlikkus, mis on kahtlemata üks efektiivse keeleõppe eeldusi.

Õppijate tähelepanekud oma emakeele ja sihtkeelte erinevuste ning sarnasuste kohta langesid paljuski kokku keelte tüpoloogiliste struktuurierinevustega. Teisisõnu, tegeliku ja tunnetatud sarnasuse ning erinevuse vahel ei olnud õppijate arusaamade põhjal olulist lahknevust, kui tegemist oli keelestruktuuride ja -kasutuse võrdlusega üldisemal tasandil. Samuti ei olnud erinevusi eesti- ja soomekeelsete õppijate arusaamades: selgelt teadvustati soomeugri- ja indoeuroopa keelte eripära ning lähedaste soomeugri keelte omavaheline sarnasus võrdluses indoeuroopa keeltega; samas osati eesti ja soome keele sarnasuse kõrval näha ka nendevahelisi erinevusi. Eesti ja soome keele omavaheline sarnasus nii struktuurielementide kui toimimismehhanismide osas ilmnes eelkõige võrdluses indoeuroopa keeltega. Eesti ja soome keele võrdluses 
keskenduti keeltevahelistele struktuurierinevustele, eriti aga kultuuri- ja keelekasutuserinevustele. Seega teadvustatakse lähedaste sugulaskeelte omavahelist sarnasust võrdluses kaugemate keeltega, mitte niivõrd nende omavahelises võrdluses.

Käesoleva uurimuses ilmnenud õppijate tähelepanekutele ja arusaamadele on senisest enam põhjust toetuda nii ema- kui võõrkeeleõppes. Emakeeleõpetuse roll metalingvistilise teadlikkuse kujundajana võiks olla senisest suurem: just emakeeleõpetuse kaudu kujuneb õppijal baas võõrkeeleõppeks, arusaam keele struktuurist ja toimimismehhanismidest, mis aktiveerub võõrkeeleõppe käigus. Õpetaja ülesanne ei tohiks olla vaid valmis teadmiste jagamine, vaid ta peaks teadvustama, väärtustama ja selgitama neid teadmisi, arusaamu, kogemusi ja intuitsiooni, mis õppijatel varasemast juba olemas on. Samuti ei ole lähedase sugulaskeele õppimisel põhjust keskenduda vaid keelte omavahelises võrdluses ilmnevatele erinevustele, vaid ka võrdluses tüpoloogiliselt erinevate keeltega ilmnevatele sarnasustele. Lähedaste sugulaskeelte õppimise ja õpetamise võtmeküsimus on õppija metalingvistiline teadlikkus: õppija peab teadma, millal ja kuivõrd võib ta sihtkeelt kasutades tugineda emakeelele ning millal mitte.

\section{Kirjandus}

Dufva, Hannele, Mika Lähteenmäki, Sari Isoherranen 1996. Elämää kielen kanssa. Arkikäsityksiä kielestä, sen oppimisesta ja opettamisesta. Jyväskylä: Soveltavan kielentutkimuksen keskus.

James, Carl, Peter Garret 1991. Language Awareness in the Classroom. London: Longman.

Jong, Nivja de, Margarita Steinel, Arjen Florijn, Jan Hulstijn, Rob Schoonen 2009. To what extend (psycho)linguistic abilities determine communicative skills? Ettekanne 15. rakenduslingvistika maailmakongressil Essenis 25.8.2008.

Kaikkonen, Pauli 2004. Vierauden keskellä: vierauden, monikulttuurisuuden ja kulttuurienvälisen kasvatuksen aineksia. Jyväskylä: Jyväskylän yliopisto.

Kaivapalu, Annekatrin, Pirkko Muikku-Werner 2000. Eesti ja soome (üli)õpilaste arvamusi emakeelest. - Emakeele Seltsi aastaraamat 44-45, 83-106. 
Kaivapalu, Annekatrin 2005. Lähdekieli kielenoppimisen apuna. Jyväskylä Studies in Humanities 44. Jyväskylä: Jyväskylän yliopisto.

Kaivapalu, Annekatrin 2006. Emakeel võõrkeeleõppes - eelis või takistus? - Oma Keel 1, 16-26.

Kaivapalu, Annekatrin 2007. Äidinkieli vieraiden kielten opiskelussa - etu vai haitta? Oppijoiden käsityksiä lähdekielen vaikutuksesta kohdekielen oppimiseen teorioiden ja tutkimistulosten valossa. - Olli-Pekka Salo, Tarja Nikula, Paula Kalaja (Toim.). Kieli oppimisessa - Language in Learning. AFinLA:n vuosikirja 65. Jyväskylä: AFinLA, 298-309.

Kaivapalu, Annekatrin 2008. Lähtekeele mõju korpuspõhine uurimine. - Pille Eslon (Toim.). Õppijakeele analüus: võimalused, probleemid, vajadused. Tallinna Ülikooli eesti filoloogia osakonna toimetised 10. Tallinn: TLÜ Kirjastus, 93-119.

Kalaja, Paula 1995. Vieraiden kielten oppijoiden metakognitiivinen tieto, mitä se oikeastaan on? - Pirkko-Muikku Werner, Kyösti Julkunen (Toim.). Kielten väliset kontaktit. AFinLA:n vuosikirja 53. Jyväskylä: AFinLA, 65-75.

Kalaja, Paula, Ana M. F. Barcelos 2003. Beliefs about SLA: New Research Approaches. Dordrecht: Kluver Academic Press.

Kalaja, Paula, Hannele Dufva, Riika Alanen 2005. Käsitykset kielenoppimisesta oppijan ja opettajan työkalu. - Viljo Kohonen (Toim.). Eurooppalainen kielisalkku Suomessa: tutkimus- ja kehittämistyön taustaa ja tuloksia. Helsinki: WSOY, 295-314.

MacWhinney, Brian 1990. Psycholinguistics and foreign language acquisition. Jorma Tommola (Toim.). Vieraan kielen ymmärtäminen ja tuottaminen. AFinLA:n vuosikirja 48. Turku: AFinLA, 71-78.

Martin, Maisa 1995. The Map and the Rope. Finnish Nominal Inflection as a Learning Target. Studia Philologica Jyväskyläensia 38. Jyväskylä: University of Jyväskylä.

Martin, Martin 1996a. Morfological Production and Descriptions of Finnish. Kari Sajavaara, Courtney Fairweather (Eds.). Approaches to Second Language Acquisition. Jyväskylä Cross-language Studies. Jyväskylä: University of Jyväskylä, 187-193.

Martin, Maisa 1996b. Miksi suomi on niin helppo kieli? - Seppo Pekkola (Toim.). Kuuskymppinen. Suomen kielen laitoksen julkaisuja 38. Jyväskylä: Jyväskylän yliopisto, $110-125$.

Muikku-Werner, Pirkko 1998. Äidinkieli suomen kielen ja vieraiden kielten opiskelijoiden mielissä. - Minna-Riitta Luukka, Sigrid Salla, Hannele Dufva 
(Toim.). Puolin ja toisin. Suomalais-virolaista kielentutkimusta. AFinLA:n vuosikirja 56. Jyväskylä: AFinLA, 219-233.

Odlin, Terrence 1996. On the recognition of transfer errors. - Language Awareness 5: 3; 4, 166-178.

Pavlenko, Anita, James P. Lantolf 2002. Second language learning as participation and (re)construction of selves. - James P. Lantolf (Ed.). Sociocultural Theory and Second Language Learning. Oxford: Oxford Unversity Press, 155-177.

Remes, Hannu 2009. Muodot kontrastissa. Suomen ja viron vertailevaa taivutusmorfologiaa. Acta Universitatis Ouluensis Humaniora B 90. Oulu: Oulun yliopisto.

Ringbom, Håkan 2007. Cross-linguistic Similarity in Foreign Language Learning. Clevedon: Multilingual Matters LTD.

Sajavaara, Kari 2006. Kontrastiivinen analyysi, transfer ja toisen kielen oppiminen. - Annekatrin Kaivapalu, Külvi Pruuli (Toim.). Lähivertailuja 17. Jyväskylä Studies in Humanities 53. Jyväskylä: Jyväskylän yliopisto, 43-60.

Sulkala, Helena 1996. Finnish as a Second Language for Speakers of Related Languages. - Maisa Martin, Pirkko Muikku-Werner (Toim.). Finnish and Estonian - New Target Languages. Jyväskylä: Jyväskylän yliopisto, 143-157.

Wenden, A. 1987. Metacognition: An expanded view of the cognitive abilities of L2 learners. - Language Learning 37, 573-597. doi:10.1111/j.1467-1770.1987. tb00585.x

\section{Annekatrin Kaivapalu}

Tallinna Ülikool, eesti keele ja kultuuri instituut

Narva mnt 29

10120 Tallinn, Estonia

kaivapa@tlu.ee 


\title{
Metalinguistic awareness in foreign language learning: the first language reflected by target languages
}

\author{
ANNEKATRIN KAIVAPALU \\ Tallinn University
}

The paper deals with one of the aspects of metalinguistic awareness: raising consciousness about learners' first language during the learning process of foreign and/or second languages. The aim of the study was to explore what kind of observations learners make and what views they have about their first language, Estonian and Finnish. To study these views data was gathered from students of Jyväskylä and Tallinn Universities. The participants of the study were asked to write essays to discuss whether the L1 of the learner supports or impedes the learning of L2. The first languages of the learners were Estonian and Finnish; the target languages they had studied Estonian, Finnish, Finnish sign language; English, German, Swedish, Norwegian; French, Spanish, Portuguese, Italian; Russian, Polish, and Bulgarian. The study focuses mainly on the relations between actual and assumed crosslinguistic similarity and difference: one aim of the study was to find out if the learners' views are in correspondence with typological similarities and differences.

The results of the study show considerable agreement between the learners' views about differences and similarities between the first and target languages and typological descriptions of languages. While learning Indo-European languages the Estonian and Finnish learners observed mainly similarities in structure as well as in function principles of two Finno-Ugric languages and their differences in comparison with Indo-European languages. The observations included all levels of Estonian and Finnish, but focused especially on morphological systems of both languages. While comparing Estonian and Finnish the learners observed mainly the few structural differences there are between the languages, but also differences in language use.

Keywords: metalinguistic awareness; learners' views; foreign language learning; cross-linguistic actual and perceived similarity and difference; Estonian; Finnish 